\title{
Pancreatic encephalopathy
}

\author{
B. SHARF AND E. BENTAL
}

From the Department of Neurology, Rothschild Municipal-Government Hospital, Haifa, Israel

SUMMARY A 58 year old woman presenting with abdominal distress and a neuropsychiatric disturbance with evidence of focal neurological deficit is described. A diagnosis of pancreatic encephalopathy was made, and the patient was treated accordingly with pancreatic anti-enzymes. A survey of the literature is presented.

The syndrome of pancreatic encephalopathy was first described by Rothermich and von Haam in 1941 and Vogel $(1950,1951 a$ and $b)$ investigated the pathogenesis of this condition. A few cases have been published, but the pathophysiology of the disease has not been completely elucidated. Because of the high mortality and the therapeutic value of the anti-enzymes, early diagnosis and treatment are essential.

\section{CASE REPORT}

A 58 year old woman was admitted as an emergency case to the surgical department, complaining of severe abdominal pain, nausea, and constipation. The onset of pain was sudden, 12 hours before admission. It was localized to the upper abdomen, and accompanied by vomiting. From her previous history it emerged that she was suffering from latent diabetes. Thirteen years before admission she had undergone gynaecological surgery for a prolapse of the vaginal vault, and three years before admission she had undergone an appendicectomy.

On physical examination there was tenderness to palpation in the periumbilical area but the abdomen was soft, and active peristaltic sounds were audible. No other physical signs were elicited. The day after admission the patient became confused and afterwards stopped talking entirely. Straight radiographs of the abdomen, as well as an electrocardiogram, were within normal limits.

The haemoglobin level was $13.4 \mathrm{~g} / 100 \mathrm{ml}$., a leucocyte count was $24,000 /$ c.mm, plasma glucose was 95 $\mathrm{mg} / 100 \mathrm{ml}$. and urea $43 \mathrm{mg} / 100 \mathrm{ml}$. Plasma sodium level was $134 \mathrm{~m}$-equiv/l.; chlorides were $98 \mathrm{~m}$-equiv/l. The $\mathrm{CO}_{2}$ combining power was 20 volumes; plasma potassium $4.8 \mathrm{~m}$-equiv/l.; cholesterol $285 \mathrm{mg} / 100 \mathrm{ml}$. The thymol turbidity was $1 \mathrm{u}$.; transaminase $21 \mathrm{u}$.; alkaline phosphatase 1.7 Bodansky units. Plasma calcium was not estimated. The serum amylase was 960 Somogy units. Urine examination revealed protein and few erythrocytes and leucocytes per high power field.

The clinical presentation and the high serum amylase indicated a probable diagnosis of acute pancreatitis and therefore, 48 hours after admission, treatment with aprotinin $^{1} 200,000$ units/day was commenced. Her general condition improved and on the fourth day of treatment the leucocyte count went down to $11,000 / \mathrm{c} . \mathrm{mm}$ and serum amylase to 185 units. The serum proteins and the liver function tests were normal, and the abnormal urine findings had disappeared.

Nine days after her admission a neurological examination was requested because of a mental state described as 'confusion'. On examination the patient was conscious but only partly cooperative. She did not execute simple commands, and replied to every question by saying 'yes', appearing not to understand the question. She was incapable of writing and did not appear to be concerned by her situation. The clinical picture was that of motor and sensory aphasia. A mild degree of right central facial paresis and a slight weakness of the right arm were evident. An EEG record was found to be abnormal, with irregularity of the background activity and slow focal high voltage theta and delta waves over the left frontoparietal region.

Lumbar puncture showed clear CSF at a pressure of $120 \mathrm{~mm}$ water. It contained 28 lymphocytes per c.mm. Protein level was $50 \mathrm{mg} / 100 \mathrm{ml}$. and glucose $80 \mathrm{mg} /$ $100 \mathrm{ml}$. The level of chloride was $126 \mathrm{~m}$-equiv/l. and transaminase 12 units. A cytological examination of the CSF did not reveal malignant cells. Radiographs of skull and chest were normal. Radioactive scanning of the brain with Indium $113^{m}$ was performed, and two pathological concentrations were seen in the left hemisphere, the one in the frontoparietal region and the other somewhat posteriorly (Fig. 1).

The patient's condition deteriorated into a state of akinetic mutism with incontinence of faeces and urine. Re-examination showed no progression of the slight right hemiparesis described above. However, tenderness of the skull on the left side, and a palmomental reflex on the right side had appeared. The aphasia remained unchanged.

A left carotid angiogram revealed a considerable deviation of the anterior cerebral artery from left to

${ }^{1}$ Trasylol, Bayer. 


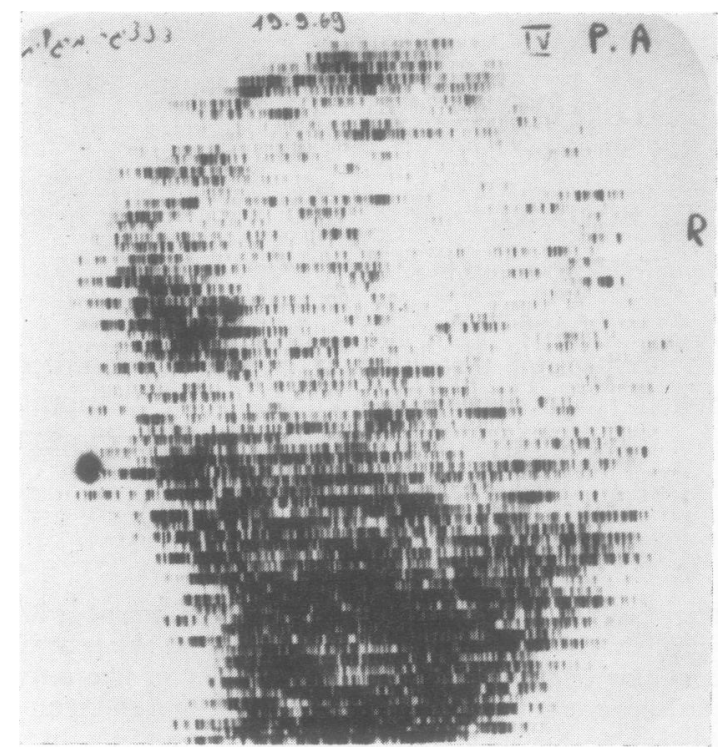

FIG. 1. Brain-scan with Indium $113^{m}$ showing pathological concentration in the left hemisphere.

right, but the middle cerebral artery and the Sylvian point were in normal position (Fig. 2a). The lateral projection showed no deviation of the blood vessels (Fig. 2b). Radiographs of the skeleton, barium meal and follow-through, and cholecystogram were normal. A pneumoencephalogram showed normal filling of the cerebral ventricles (Fig. 3). Repeat electroencephalographic recordings showed progression with increasingly marked lateralization to the left frontoparietal region (Fig. 4). Blood complement fixation tests for adenoviruses, Q-fever, and ornithosis were negative. The serum amylase had fallen to 73 units.

Six weeks after admission the patient gradually started to say a few words and in the following week there was a slow but gradual improvement of her sensory and motor dysphasia.

She was discharged from the hospital and was followed-up as an outpatient. During the ensuing weeks, the amelioration of her speech functions continued, she started to talk rationally, to understand, and to read. She still demonstrated a mild motor dysphasia.

Three months later she was readmitted to the department for further evaluation. On physical examination there were no abnormal findings except for the slight dysphasic disturbance as before. An EEG record was within normal limits and a brain scan showed only slight concentration in the left temporoparietal region, much less than in the previous scan. A repeat left carotid angiogram revealed normal filling of the brain vessels, without any deviation (Fig. 5). The patient was discharged in good general condition and was able to resume her normal daily activities.

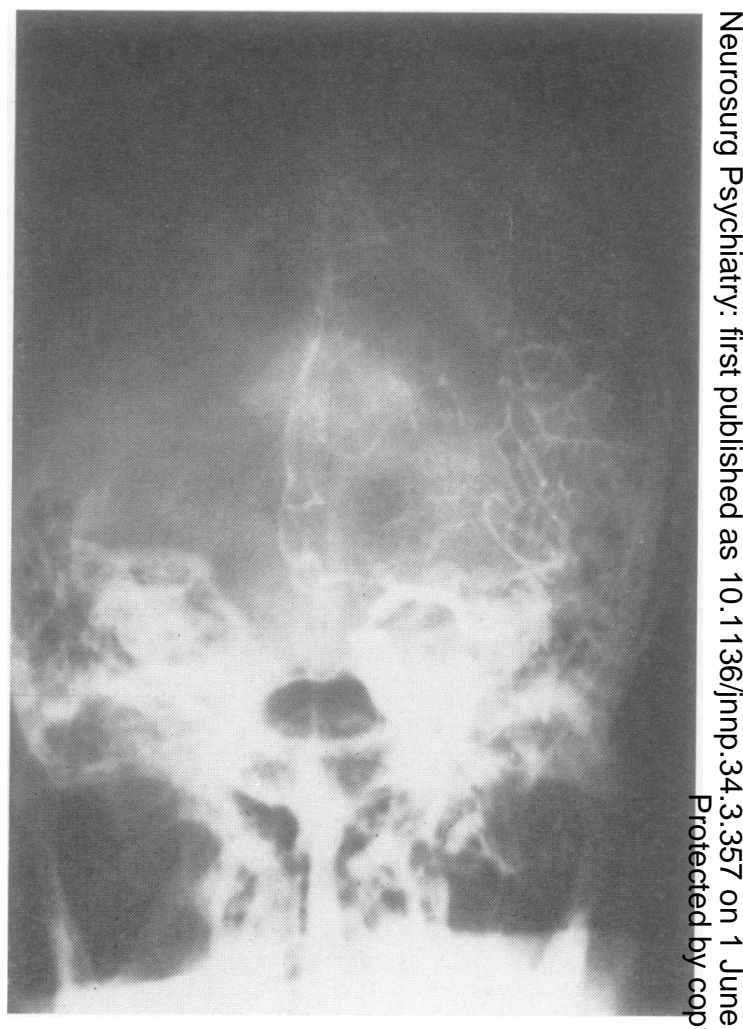

FIG. 2a. First angiogram: anteroposterior projection. Marked displacement of the anterior cerebral artery.

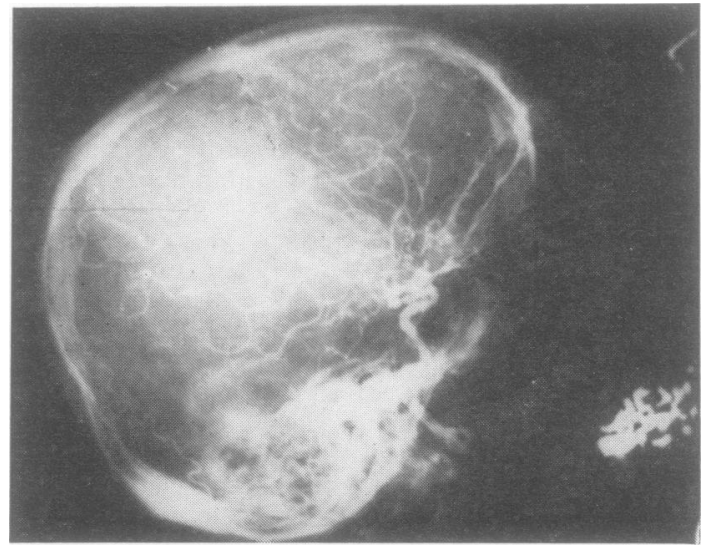

FIG. 2b. First angiogram: lateral projection. 

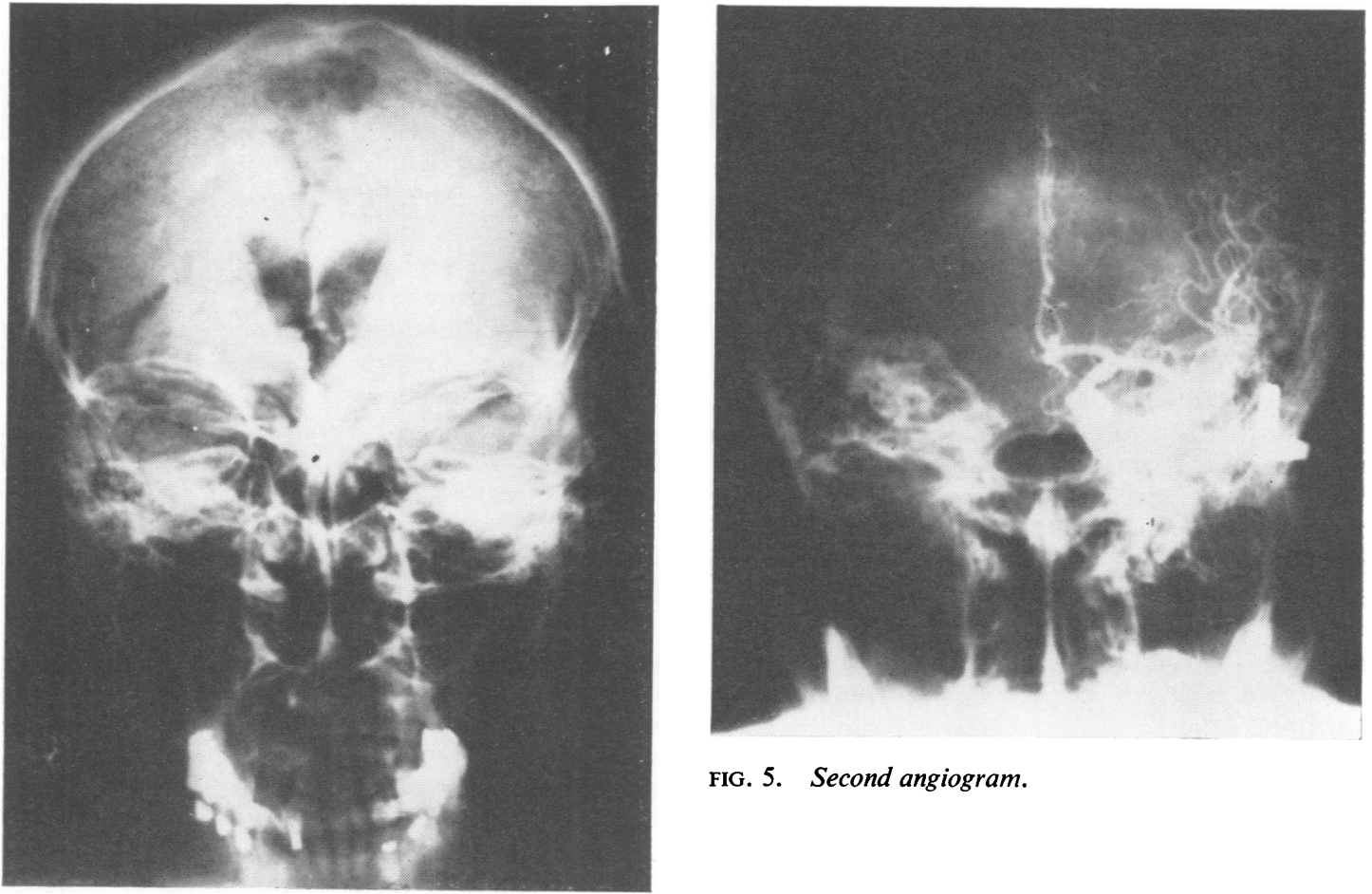

FIG. 5. Second angiogram.

FIG. 3. Pneumoencephalogram.

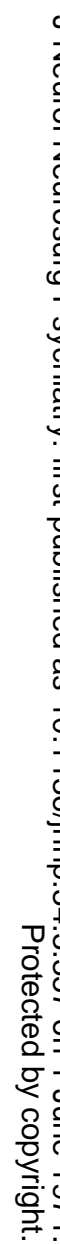

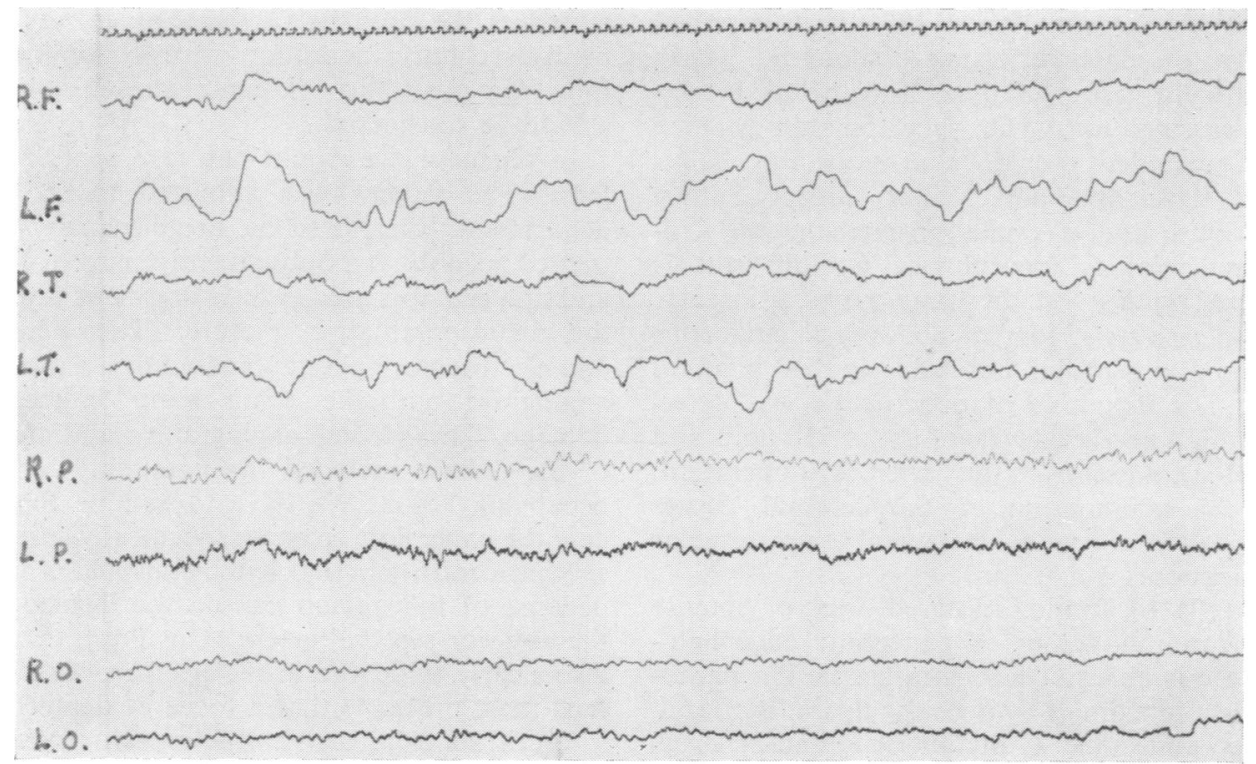

FIG. 4. EEG showing lateralization to the left frontotemporal region. 


\section{DISCUSSION}

Acute pancreatitis is not a rare condition. Avery Jones (1968) recorded 117 cases over a period of six years at the Central Middlesex Hospital. Because of the inflammatory process, pancreatic tissue is damaged and its enzymes liberated. These are absorbed into the circulation, where they result in the clinical and pathological consequences of this condition. Clinically the cardinal symptom is a sudden and severe pain in the upper abdomen. The diagnostic laboratory examination is the rise of serum amylase to 1,000 units or more. This high level is often of short duration. The serum amylase also rises in other conditions such as perforated peptic ulcer, cholecystitis, or intestinal obstruction, but to a lower level than in pancreatitis. In severe cases of pancreatitis, a low serum calcium is sometimes found, which is due to a soap formation consequent to the diffuse retroperitoneal fatty necrosis. The differential diagnosis should include perforated peptic ulcer, coronary thrombosis, and gall-stone colic.

Most authors agree that the high serum amylase is the main diagnostic criterion. Apart from symptomatic treatment, specific anti-enzymes, aiming to neutralize the destructive action of the released enzymes, have been used. One of the anti-enzymes, aprotinin (Trasylol), is a low molecular weight polypeptide produced from parotid gland or lung tissue. Trasylol inhibits the action of trypsin, chymotrypsin, kallikrein, fibrinolysin, and other proteolytic enzymes.

Rothermich and von Haam (1941) first described the entity of pancreatic encephalopathy. They presented eight cases. Of these, five included postmortem examination. The symptomatology they described included mental confusion and hallucinations, dysarthria and stutter, anxiety, short lucid periods, and a cyclic progression with remission and relapses. Neurological findings in their cases were rigidity of the four limbs, muscular aches, hyper-reflexia, loss of abdominal cutaneous reflexes, and occasional Babinski sign or bilateral grasping. The diagnosis of pancreatitis was determined by high amylase levels of about 750 units and the pathological lesions in the pancreas at operation. Histological examination of the cerebral tissues revealed diffuse petechiae and perivascular demyelinization.

Vogel (1951b), found scattered foci of intense demyelinization in cases of pancreatic encephalopathy. He was able to demonstrate a similar pathological effect in animals by injecting lipase. Bertrand, Cerbonnet, and Godet-Guillain (1958) and Delarue, Chomette, Monsaingeon, Pinaudeau, and Bro- cheriou (1956), found areas of cerebral malacia with $\frac{}{z}$ diffuse demyelinization, a macrophagic reaction and multiple petechiae in the cortex, thalamus, and brain-stem in pancreatic encephalopathy.

In 1967 Brion, Aillet, Graveleau, and Léonardon published a case without laboratory evidence which ${ }_{0}^{0}$ they called 'Encéphalopathie pancréatique probable guérie par les antitrypsiques'. The clinical picture in this case was encephalitic with a hallucinatory state, $\vec{z}$ convulsive seizures, bilateral clonus and Babinski signs, and a diffuse dysrhythmia with slowing in the EEG. Because of abdominal pains, the possibility of $\overrightarrow{0}$ pancreatic encephalopathy was considered, and a $\frac{}{\sigma}$ therapeutic trial with anti-enzymes resulted in a $\frac{\overline{\bar{c}}}{\vec{D}}$ spectacular remission. Another publication in the $\mathbb{\otimes}$ French literature, that of Goulon, Julien, Rapin, Nouailhat, and Barois (1967), presented three more कs cases of pancreatic encephalopathy. His CSF $\vec{\circ}$ findings were similar to ours.

Reviewing these few publications on pancreatic encephalopathy, the characteristic picture evolves of an acute delirium with diffuse neurological and electroencephalographic signs. The encephalopathy $\dot{\omega}$ usually begins between the second and the fifth dapi $\omega$ of the pancreatitis. It is most probably caused bo w the toxic effects of the enzymes on the brain, and $y$ not by hypoglycaemia, hyperosmolarity, or electr\& 의 lyte disturbances. The pathological picture is mainl $\vec{E}$ that of a widespread demyelinization and diffuse $\subseteq$ haemorrhages in the brain. The poor prognosis the untreated condition and the therapeutic value $\overrightarrow{0}$ of the anti-enzymes emphasize the importance of correct diagnosis. Early treatment with anti-enzymes improves the prognosis. Therefore in any atypical neuropsychiatric condition with abdominal symptoms the possibility of pancreatic encephalopathy should be considered.

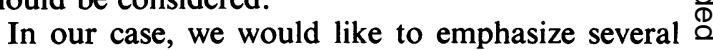
facts. The patient was admitted to the surgical $\overrightarrow{\overrightarrow{0}}$ department, diagnosed as acute pancreatitis and 3 treated accordingly. Subsequently signs of confusion and aphasia appeared, which drew our attention to the neuropsychiatric picture. The neurological and electroencephalographic findings, as well as the angiogram and the brain scan, indicated brain $\frac{0}{7}$ damage. The second angiography and the course 3 of the disease excluded the possibility of a space- 8 occupying lesion. We have to assume that in this case the pancreatic enzymes specifically damaged the $ᄋ$ speech centre in the left hemisphere, and that oedema of this region caused the displacement of the anterior cerebral artery. This brain damage was also clearly evidenced in the electroencephalograms. of It is most probable that a focus of demyelinization $N$ in a critical area, such as the speech centre, caused ్ㅓ severe aphasic disturbances. Because of the aphasia 
it was difficult to evaluate the psychiatric state of the patient. It should be pointed out that the patient described showed a less severe encephalopathic picture than is usually described in the literature, possibly due to the fact that anti-enzyme treatment was started early.

A survey of the literature at our disposal revealed no references to pancreatic encephalopathy with focal signs.

\section{REFERENCES}

Bertrand, I., Cerbonnet, G., and Godet-Guillain, J. (1958). Contribution a l'étude des encéphalopathies d'origine pancréatique. Rev. neurol., 98, 245-262.

Brion, S., Aillet, J., Graveleau, J., and Léonardon, N. (1967). Encéphalopathie pancréatique probable guérie par les antitrypsiques. Rev. neurol., 116, 691-693.

Brion, S., Aillet, J., Graveleau, J., and Léonardon, N. (1968). Encéphalopathie pancreatique probable guérie par les antitrypsiques. Presse méd., 76, 9-12.

Delarue, J., Chomette, G., Monsaingeon, A., Pinaudeau, Y., and Brocheriou, Cl. (1965). Encéphalopathie subaiguë secondaire à une pancréatite nécrosante hémorragique. Arch. Anat. Path., 13, 45-47.

Goulon, M., Julien, C. G., Rapin, M., Nouailhat, F., and Barois, A. (1967). L'encéphalopathie pancréatique. A propos de trois observations. Rev. neurol., 117, 363-372.

Jones, F. A., Gummer, J. W. P., and Lennard-Jones, J. E. (1968). Clinical Gastroenterology. 2nd edn. Blackwell Scientific Publications: Oxford.

Nugent, F. W., Warren, K. W., Jonasson, H., and Garcia de Paredes, G. (1963). Early experience with Trasylol in the treatment of acute pancreatitis. (Abstract.) Gastroenterology, 44, 846.

Rothermich, N. O., and von Haam, E. (1941). Pancreatic encephalopathy. J. clin. Endocr., 1, 872-881.

Vogel, F. S. (1950). Demyelinization induced experimentally by means of lipase. (Abstract.) Fed. Proc., 9, 347.

Vogel, F. S. (1951a). Demyelinization induced in living rabbits by means of a lipolytic enzyme preparation. J. exper. Med., 93, 297-304.

Vogel, F. S. (1951b). Cerebral demyelination and focal visceral lesions in a case of acute haemorrhagic pancreatitis with a consideration of the possible role of circulating enzymes in the causation of the lesions. A.M.A. Arch. Path., 52, 355-362. 